\title{
Dietary Selenium for the counteraction of oxidative damage: fortified foods or supplements?
}

\author{
Alessandra Bordoni ${ }^{1 *}$, Francesca Danesi ${ }^{1}$, Marco Malaguti ${ }^{1}$, Mattia Di Nunzio ${ }^{1}$, Francesca Pasqui ${ }^{2}$, \\ Magda Maranesi ${ }^{1}$ and Pier Luigi Biagi ${ }^{1}$ \\ ${ }^{1}$ Research Centre on Nutrition and Vitaminology, Department of Biochemistry "G. Moruzzi”, University of Bologna, via Irnerio, \\ 48 - 40126 Bologna, Italy \\ ${ }^{2}$ Department of Internal Medicine and Gastroenterology, Policlinico S. Orsola-Malpighi, University of Bologna, via Massarenti, \\ 9 - 40138 Bologna, Italy
}

(Received 7 February 2007 - Revised 3 May 2007 - Accepted 8 June 2007)

Since any significant modification in the Se status, leading to changes in the activity of the seleno-enzymes, may have important consequences on the susceptibility of tissues to oxidative stress, considerable efforts have been made upon increasing Se dietary intake. In this respect, an important debate is still open about the bioavailability and the effectiveness of Se, and more generally nutrients, in supplements compared with foods. Using male Wistar rats, we have compared the effectiveness of two different diets in which an adequate Se content $(0 \cdot 1 \mathrm{mg} / \mathrm{kg})$ was achieved by adding the element as sodium selenite or as component of a lyophilized Se-enriched food, in the counteraction of an oxidative stress induced by intraperitoneal administration of adriamycin. Both Se-enriched diets were able to reduce the consequences of the oxidative stress in liver, mainly by increasing glutathione peroxidase activity. This increase was more evident in rats fed on the diet enriched with the lyophilized food, probably due to the different chemical forms of Se, or to other components of the food itself. Although further studies are needed, data herein presented may contribute to the characterization of the effectiveness of Se from different sources, foods or supplements, in the light of dietary advice to the population concerning improvement of Se intake.

Selenium: Oxidative stress: Selenium-enriched food: Sodium selenite

Since oxidative stress is considered to be implicated in the ethiopathology of many chronic diseases, considerable efforts have been made upon using antioxidants to counteract free radicals, and nutritional strategies designed to increase cellular defence systems have been identified as a promising approach to minimize oxidative stress associated disease conditions ${ }^{1,2}$. In this respect, dietary supplementation with Se could offer protection in preventing free radical-induced diseases.

$\mathrm{Se}$ in the form of selenocysteine is part of the active centre of several seleno-enzymes which have antioxidant function, e.g. the glutathione peroxidases (GPx), the deiodinases and the thioredoxine reductases ${ }^{3}$. It is documented that any significant modification of the Se status would lead to changes in the activity of the seleno-enzymes and have important consequences on the susceptibility of tissues to oxidative stress ${ }^{4,5}$.

Regarding nutritional supplementation, an important debate is still open about the bioavailability and the effectiveness of nutrients in supplements compared with foods. Foods are complex matrices, and the interaction of one component with other components may either enhance or reduce its availability, and therefore its effectiveness. It is demonstrated that Se activity, particularly in chemoprevention, depends not only on the dose, but also on the chemical form in which it is administered 6 .

In this study, we have evaluated in rats the possibility of a nutritional counteraction of an oxidative stress by two different experimental diets in which an adequate Se content was achieved by adding to a standard diet for rats the element in pure chemical form (as sodium selenite) or as component of a lyophilized Se-enriched food. The oxidative stress was induced by intraperitoneal injection of adriamycin (ADR).

Different parameters related to oxidative stress and antioxidant defences were measured in blood and liver of rats receiving the experimental diets or the standard one; furthermore, since it has been reported that the activity of the fatty acid desaturating enzymes is influenced by $\mathrm{Se}^{7}$, liver fatty acid composition was evaluated.

\section{Experimental methods}

Materials

Diets were prepared by Mucedola (Milano, Italy). ADR was from Pharmacia (Milano, Italy). All chemicals and solvents

Abbreviations: ADR, adriamycin; GSH, glutathione; GPx, glutathione peroxidase; ROM, reactive oxygen metabolites; TAA, total antioxidant activity; St, standard diet; E1, E2, Se-enriched diets.

* Corresponding author: Alessandra Bordoni, fax +39051 2091235, email alessandra.bordoni@unibo.it 
were purchased from Sigma Chemical Co. (St. Louis, MO, USA) and were of the highest analytical grade.

\section{Animals and diets}

Thirty male Wistar rats aged $21 \mathrm{~d}$ were used. After $4 \mathrm{~d}$ on a standard diet, they were randomly divided into three groups, one fed ad libitum on the standard diet $(\mathrm{St})$ and the other two fed on one of the experimental Se-enriched diets (E1 or E2). Se content was $0.05 \mathrm{mg} / \mathrm{kg}$ in the St diet, and $0.1 \mathrm{mg} / \mathrm{kg}$ in both the experimental ones. In the E1 diet Se was supplemented as sodium selenite, while in the E2 diet by the addition of the lyophilized form of a common food having a high Se content. The food used was a potato commercially available in Italy, in which the Se content is increased by foliar Se supplementation during plant growth ${ }^{8}$.

Food lyophilization was obtained by two 24-h cycles using a Drywinner 3 lyophilizer (Heto-Holten/Jouan Nordic, Hallerød, Denmark). The Se concentration in the lyophilized food was $0.0882 \mu \mathrm{g} / \mathrm{g}$, as determined by inductively coupled plasma-atomic emission spectrometry ${ }^{9}$. Both sodium selenite and lyophilized food were added in appropriate amounts to diets during their preparation to obtain a Se final concentration of $0.1 \mathrm{mg} / \mathrm{kg}$ diet. Protein, lipid and carbohydrate content was in the normal range of adequacy for rats $(\mathrm{g} / 100 \mathrm{~g}$ diet): proteins about 21 ; lipids about 8 ; carbohydrates about 61.5 , and contained appropriate amounts of vitamins and other minerals.

Animals were housed in individual cages in strictly controlled conditions of temperature $\left(20 \pm 2^{\circ} \mathrm{C}\right)$ and humidity (60-70\%), with a 12-h dark-light cycle. Water and food were provided ad libitum; food consumption was measured every day, and rat body weight every week.

After $60 \mathrm{~d}$ dietary treatment, rats of each group were divided into two subgroups, one receiving intraperitoneally ADR $(10 \mathrm{mg} / \mathrm{kg}$ body weight), and the other a similar volume of physiological solution. ADR is an anthracycline antibiotic widely used in the treatment of human malignancies; similar to most of the anticancer drugs, it causes various toxic effects, and its cytotoxicity is mediated by the formation of an iron anthracycline complex that generates free radicals ${ }^{10}$.

After $48 \mathrm{~h}$ animals were sacrificed with anaesthetic ether. Blood was sampled, and the liver was quickly excised, washed in PBS, weighed, and immediately frozen at $-80^{\circ} \mathrm{C}$. The Animal Care Committee of the University of Bologna approved the study.

\section{Methods}

Concentration of reactive oxygen metabolites (ROM). ROM were measured by the d-ROM test (Diacron, Grosseto, Italy $)^{11}$, which is based on the ability of transition metals to react with peroxides by the Fenton reaction. The reaction produces free radicals which, trapped by an alchilamine, form a coloured compound detectable at $505 \mathrm{~nm}$. The test was applied directly on plasma samples and on samples obtained from about $1 \mathrm{~g}$ liver after lipid extraction according to Folch et al. ${ }^{12}$.

Total antioxidant activity (TAA). TAA was measured using the method of $\operatorname{Re}$ et $a l^{13}$, on the basis of the ability of the antioxidant molecules in the sample to reduce the radical cation of 2,2' -azino-bis-(3-ethylbenzothiazoline-6-sulfonic acid) (ABTS), determined by the decolourization of $\mathrm{ABTS}^{\circ+}$, and measured as the quenching of the absorbance at $734 \mathrm{~nm}$. Values obtained for each sample were compared to the concentration-response curve of the standard trolox solution and expressed as trolox equivalent (TE). TAA was measured directly in plasma, while liver was homogenized in cold $5 \mathrm{~mm}$ potassium phosphate buffer ( $\mathrm{pH} 7 \cdot 4)$, filtered, and the resulting filtrate was used for TAA assay.

Glutathione peroxidise activity. GPx activity was assayed spectrophotometrically at $25^{\circ} \mathrm{C}$ according to Flohe \& Gunzler $^{14}$, following at $340 \mathrm{~nm}$ the disappearance of NADPH due to the reduction of oxidized glutathione $(\mathrm{GSH})$ coupled to the oxidation of NADPH. The assay was performed on both plasma and aliquots of the filtrate obtained after liver homogenization in cold buffer (50 mMTris- $\mathrm{HCl}, 0.5 \mathrm{~mm}$ EDTA, pH 8.0). One unit of GPx activity is defined as the amount of enzyme that catalyses the reduction of $1 \mu \mathrm{mol}$ $\mathrm{NADPH} / \mathrm{min}$.

Glutathione concentration. Concentration of total GSH was determined by the rate of formation of 5,5'-dithio-bis(2nitro benzoic acid) at $412 \mathrm{~nm}$ as described by Akerboom \& Sies $^{15}$. The liver was homogenized in $0 \cdot 3 \mathrm{M}$ potassium phosphate buffer $(\mathrm{pH} \mathrm{8.4})$, centrifuged at $3000 \mathrm{~g}$ for $10 \mathrm{~min}$ at $0-4{ }^{\circ} \mathrm{C}$, and the resulting supernatant was used for GSH assay. Results were expressed as $\mu \mathrm{g} \mathrm{GSH} / \mathrm{mg}$ protein.

Conjugated diene-containing lipids. The appearance of conjugated diene-containing lipids was evaluated as an index of lipid peroxidation using the method of Burton et al. ${ }^{16}$. Lipids were extracted from liver aliquots in chloroformmethanol-water (2:1:1 by volume). The chloroform layers from two extractions were combined and then dried under $\mathrm{N}_{2}$. Samples were resuspended in a known volume of acetonitrile and absorbance determined at $235 \mathrm{~nm}$.

Fatty acid composition. Total lipids were extracted from liver according to Folch et al. ${ }^{12}$, and fatty acid methyl esters were prepared from all samples according to Stoffel et al. ${ }^{17}$. The fatty acid composition of liver total lipids was determined by gas chromatography (Carlo Erba model 4160, Milan, Italy) using a capillary column $(30 \mathrm{~m} \times 0.25 \mathrm{~mm}$ internal diameter) filled with a thermostable stationary phase (SP $2340,0 \cdot 10-0 \cdot 15 \mu \mathrm{m}$ film thickness), at a programmed temperature $\left(160-210^{\circ} \mathrm{C}\right.$, with a $8^{\circ} \mathrm{C} / \mathrm{min}$ gradient), as previously reported ${ }^{18}$.

All data are means with their standard deviation. Statistical analysis was by one-way analysis of variance for comparison of the different dietary treatments in basal conditions or after ADR administration, and by Student's $t$ test for the analysis of ADR effects in the same dietary group.

\section{Results}

During the 12 weeks of the dietary treatment, food consumption was similar in all rats and no differences were detected in body and liver weight among the different groups (data not shown).

In basal conditions plasma ROM level, TAA and GPx activity were similar in all dietary groups (Table 1). ADR administration did not modify plasma GPx activity, while it significantly decreased TAA and significantly increased ROM level, independent of the dietary treatment. 
Table 1. Reactive oxygen metabolite (ROM) level, total antioxidant activity (TAA) and glutathione peroxidase (GPx) activity in plasma of rats fed on the different diets (St, standard diet; E1 and E2, Se-enriched diets) in basal condition and after adriamycin (ADR) administration†ł.

(Mean values and standard deviations for five rats)

\begin{tabular}{|c|c|c|c|c|}
\hline & \multicolumn{2}{|c|}{ Basal } & \multicolumn{2}{|c|}{+ ADR } \\
\hline & Mean & SD & Mean & SD \\
\hline \multicolumn{5}{|c|}{ ROM level (nmol ROM/ml) } \\
\hline St group & $229 \cdot 98$ & $13 \cdot 14$ & $281 \cdot 25^{\star \star \star}$ & $8 \cdot 62$ \\
\hline E1 group & $237 \cdot 56$ & $1 \cdot 21$ & $281 \cdot 81^{\star \star *}$ & $10 \cdot 31$ \\
\hline E2 group & $242 \cdot 37$ & 4.03 & $291 \cdot 37^{\star \star \star}$ & $12 \cdot 65$ \\
\hline \multicolumn{5}{|c|}{ TAA (mmol TE /ml) } \\
\hline St group & 1.45 & 0.04 & $1 \cdot 36^{* *}$ & 0.04 \\
\hline E1 group & 1.51 & 0.05 & $1 \cdot 38^{\star *}$ & 0.06 \\
\hline E2 group & 1.50 & 0.05 & $1 \cdot 33^{\star \star}$ & 0.04 \\
\hline \multicolumn{5}{|c|}{ GPx activity (mU /ml) } \\
\hline St group & $2 \cdot 15$ & 0.14 & $2 \cdot 25$ & $0 \cdot 17$ \\
\hline E1 group & $2 \cdot 13$ & 0.12 & $2 \cdot 12$ & $0 \cdot 16$ \\
\hline E2 group & $2 \cdot 03$ & $0 \cdot 22$ & $2 \cdot 18$ & $0 \cdot 10$ \\
\hline \multicolumn{5}{|c|}{$\begin{array}{l}\text { †ROM level, TAA and GPx activity were measured as reported in } \\
\text { Methods, and are expressed as } \mathrm{nmol} / \mathrm{ml} \text {, mmol trolox equivalent } \\
\text { (TE)/ml, and } \mathrm{mU} / \mathrm{ml} \text {, respectively. } \\
\text { ₹ Statistical analysis was by one-way analysis of variance comparing the } \\
\text { effects of the different dietary treatments in basal conditions (NS) or } \\
\text { after ADR administration (NS), and by Student's } t \text { test to evaluate the } \\
\text { effect of ADR administration in the same dietary group ( }{ }^{\star \star} P<0.01 \text {; } \\
\star \star \star P<0.001) \text {. }\end{array}$} \\
\hline
\end{tabular}

In basal conditions, no differences in liver ROM level were detected among the dietary groups; ADR administration caused a significant increase in ROM level in all rats, but higher in St group $(P<0.01)$ than in the two experimental ones $(P<0.05)$. As a result, ROM level was significantly different $(P<0.001)$ after ADR administration among the three dietary groups (Fig. 1(A)). Lipid peroxidation, evaluated as conjugated diene containing lipids, was significantly influenced by the dietary treatments in both basal condition $(P<0.001)$ and after ADR administration $(P<0.05)$, being lower in E1 and E2 rats (Fig. 1(B)). Comparing the same dietary group, ADR administration did not cause modification in conjugated diene level compared to basal condition. In basal condition TAA was similar in the three dietary groups, and it significantly decreased after ADR administration in $\mathrm{St}$ group only $(P<0.01)$. Consequently, after the oxidative stress, TAA was significantly different among the dietary groups $(P<0 \cdot 01)$, being higher in E1 and E2 rats (Fig. 1(C)).

In both basal condition and after ADR administration Se enrichment of the diets significantly influenced liver GPx activity $(P<0.05$ and $P<0.01$, respectively); this appeared significantly higher in the experimental groups. Comparing the same dietary group in basal condition and after ADR administration no differences were detected (Fig. 2(A)). Similarly, liver GSH content appeared influenced by Se dietary content in both basal and oxidative conditions, being lower in $\mathrm{E} 1$ and E2 rats than in standard ones, and ADR administration did not influence it in the same dietary group (Fig. 2(B)).

Total liver fatty acid composition of rats fed on the different diets, in basal conditions and after ADR administration, is shown in Fig. 3. No differences in fatty acid content were detected among the different dietary groups in either basal or oxidative conditions, apart from arachidonic acid relative molar content, which was higher in E1 and E2 rats than in
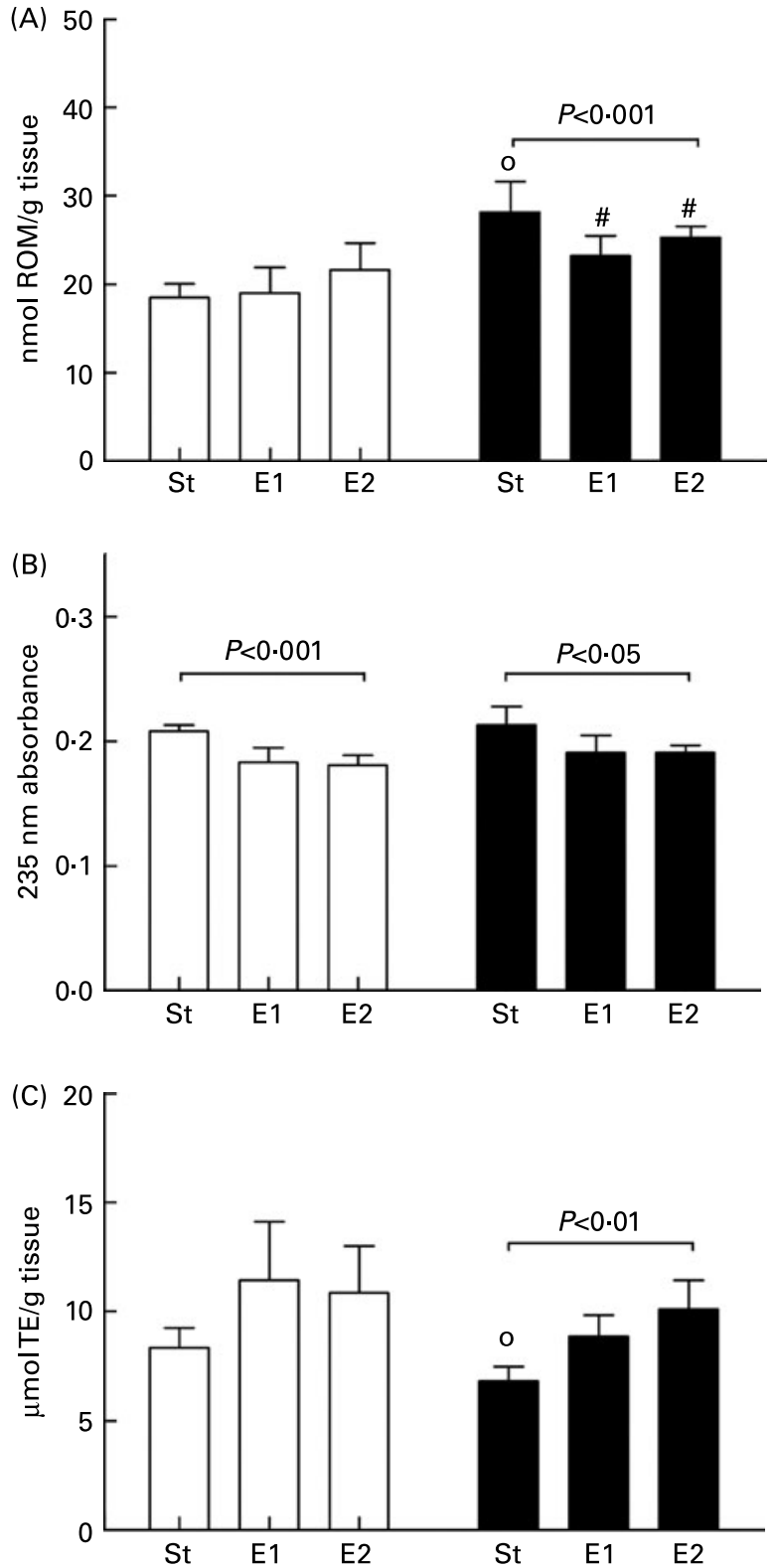

Fig. 1. Reactive oxygen metabolite (ROM) level (A), conjugated diene-containing lipids $(B)$, and total antioxidant activity (TAA; $(C)$ ) in liver of rats fed on the different diets (St, standard diet; E1 and E2, Se-enriched diets) in basal condition ( $\square$ ) and after ADR administration ( $\square$ ). ROM level, conjugated dienes and TAA were measured as reported in Methods, and are expressed as $\mathrm{nmol} \mathrm{ROM} / \mathrm{g}$ tissue, $235 \mathrm{~nm}$ absorbance (arbitrary units), and $\mu \mathrm{mol}$ trolox equivalent (TE)/g tissue, respectively. Data are means for five rats with standard deviations indicated by vertical bars. Statistical analysis was by oneway analysis of variance comparing the effects of the different dietary treatments in basal conditions (ROM level, NS; conjugated dienes, $P<0.001$; TAA, NS) or after ADR administration (ROM level, $P<0.001$; conjugated dienes, $P<0.05$; TAA, $P<0.01$ ), and by Student's $t$ test to evaluate the effect of ADR administration in the same dietary group (\#P<0.05; $O P<0.01$ ).

St ones. ADR administration did not cause any modification in fatty acid composition considering the same dietary group. No differences were detected in the unsaturation index (data not shown), while the 18:2/20:4 ratio appeared significantly lower in E1 and E2 rats than in St ones, in both basal (St 0.99 (SD 0.08), E1 0.86 (SD 0.04), E2 0.90 
(A)

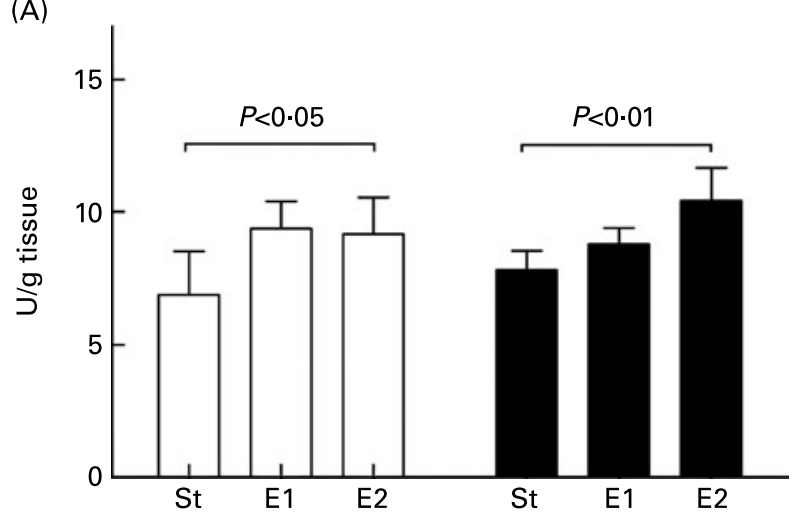

(B)

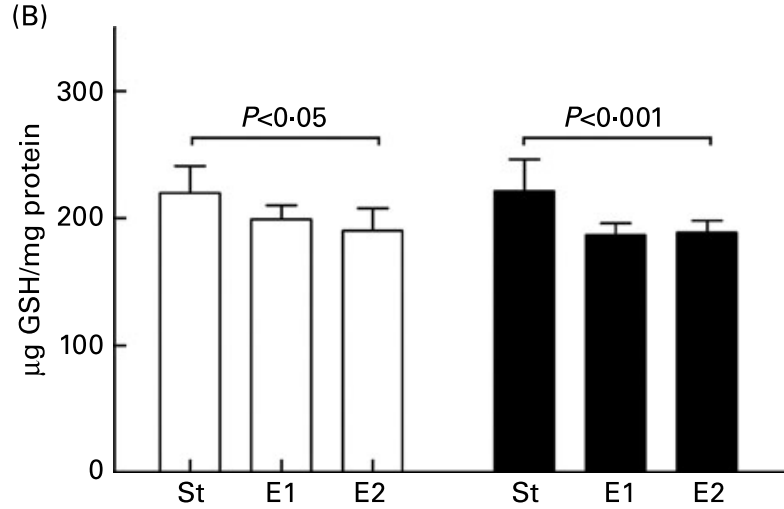

Fig. 2. Glutathione peroxidase (GPx) activity (A) and glutathione (GSH) content $(B)$ in liver of rats fed on the different diets (St, standard diet; E1 and E2, Se-enriched diets) in basal condition ( $\square$ ) and after ADR administration ( $\square$ ). GPx activity and GSH content were measured as reported in Methods and expressed as $\mathrm{U} / \mathrm{g}$ tissue and $\mu \mathrm{g} \mathrm{GSH} / \mathrm{mg}$ protein, respectively. Data are means for five rats with standard deviations indicated by vertical bars. Statistical analysis was by one-way analysis of variance comparing the effects of the different dietary treatments in basal conditions (GPx activity, $P<0.05$; GSH content, $P<0.05$ ) or after ADR administration (GPx activity, $P<0.01$; GSH content, $P<0.001$ ), and by Student's $t$ test to evaluate the effect of ADR administration in the same dietary group (NS).

(SD 0.07), $P<0.05$ ) and oxidative (St 0.98 (SD 0.06), E1 0.77 (SD 0.02), E2 0.95 (SD 0.05), $P<0.001$ ) condition.

\section{Discussion}

Se is an essential trace element which must be supplied by daily diet; its main role is that of an antioxidant in the GPx enzyme, and Se depletion results in a decrease in both GPx activity and protein levels. GPx, the main intracellular antioxidant, and other Se-dependent systems such as selenoprotein $\mathrm{P}$ and thioredoxin reductase have been reported to be critical antioxidant defences ${ }^{19,20}$.

Increased oxidative stress may be involved in the pathogenesis of many chronic diseases, and there is an obvious link between diet and oxidative stress, since the human body derives its main antioxidant defences from essential nutrients. Several studies have shown that Se deficiency adversely affects the susceptibility to different diseases, in particular cancers $^{19}$ and chronic heart failure ${ }^{20}$. The positive correlation between dietary Se and GPx expression/activity is well recognized, while the relationship between dietary Se and other selenoproteins appears ambiguous, depending on Se concentration in the diet and on the tissue considered. In fact, during dietary Se depletion there is a 'prioritization' of available Se so that synthesis of some selenoproteins is maintained more than others, and this prioritization is tissue-specific. Although in the liver thioredoxin reductase is more sensitive to Se depletion than in other tissue, in a very recent paper Crosley et $a l^{21}$ demonstrated the greatest response of GPX mRNA than other selenoprotein mRNA to decreased dietary Se in marginally deficient animals, confirming the main implication of GPx in the alteration of antioxidant defences consequent to Se depletion.

The chemical form of ingested Se partially determines the physiologic outcome in animals. Salts such selenite and selenate and the amino acid selenocysteine easily incorporate into selenoproteins, but because selenoprotein expression is tightly regulated, Se from these sources will not accumulate beyond a certain point. Because selenomethionine substitutes for methionine, it will accumulate in large protein masses such as muscle, and total Se body burden is much higher for selenomethionine than for selenocysteine or inorganic Se salts ${ }^{22}$.

Plants are able to synthesize seleno-aminoacids from selenite and selenate ${ }^{23}$, and several Se-containing compounds present in foods have been identified ${ }^{24}$. In the Se-enriched potato used as Se source in our study the majority of Se was allocated to soluble and insoluble (the residual fraction) protein fractions, according to Turakainen et l. $^{25}$. Organic Se forms are considered to be more efficient than inorganic Se forms in increasing the Se content and the activity of GPx in plasma and muscle tissue ${ }^{23}$.

Although overall absorption of all forms of Se appears relatively high ( $70 \%$ to $95 \%$ ), the bioavailability of the different forms of this trace element appears very important in the light of a dietary supplementation. Unlike other trace minerals (e.g. $\mathrm{Fe}$ and $\mathrm{Zn}$ ), the covalent nature of Se bonding precludes estimation of bioavailability of selenocompounds by simple measurements of absorption. Instead, bioavailability also must address metabolic transformation to biologically active metabolites. In this study we have compared the effects due to the dietary supplementation of the same amount of Se but in two different forms, i.e. a sodium salt, as often found in supplements, and the lyophilized form of a Se-rich potato obtained by foliar fertilization, on the counteraction of an oxidative stress induced in rats by ADR administration.

In plasma, different Se intake did not influence GPx activity, TAA and ROM level. It is demonstrated that plasma GPx activity is not strictly related to Se status ${ }^{26}$, and although we did not measure the activity of other selenoenzymes with antioxidant function such as selenoprotein $\mathrm{P}$, the invariance of plasma TAA allows speculation also of an invariance of these antioxidant proteins. This could explain the lack of protection against oxidative stress observed in plasma of E1 and E2 rats, as indicated by the similar increase of ROM level after ADR administration in all the dietary groups. This increase in plasma ROM level and the decrease in TAA observed in all rats after the anthracycline injection clearly demonstrate the onset of an oxidative condition, ROM concentration being recently indicated as a potent marker of oxidative injury ${ }^{27}$.

Similarly, the significant increase in liver ROM level observed in all dietary groups after ADR administration 


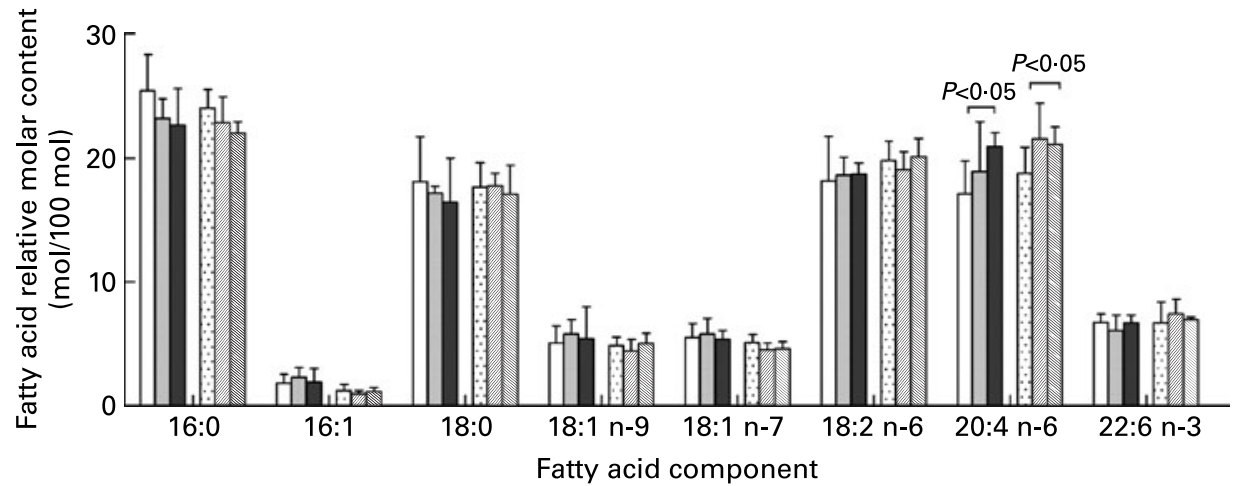

Fig. 3. Fatty acid composition of liver total lipids of rats fed on the different diets (St, standard diet; E1 and E2, Se-enriched diets), in basal condition and after

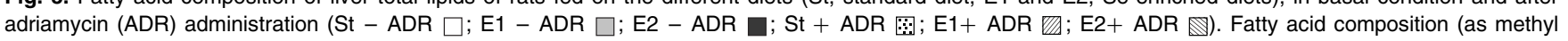
esters) was determined by gas chromatography, and expressed as $\mathrm{mol} / 100 \mathrm{~mol}$. Data are means for five rats with standard deviations indicated by vertical bars. Statistical analysis was by one-way analysis of variance comparing the effects of the different dietary treatments in basal conditions (20:4 $\mathrm{n}-6, P<0.05)$ or after ADR administration (20:4, n-6 $P<0.05)$, and by Student's $t$ test to evaluate the effect of ADR administration in the same dietary group (NS).

confirmed an oxidative condition even in this organ; nevertheless, the increase was lower in Se-supplemented rats (about $120 \%$ in both groups) than in St ones $(>150 \%)$. Since the oxidative stress was the same, it is plausible that the lower increase in ROM level was due to a partial protection by dietary Se, independent from the use of sodium selenite or lyophilized food for the supplementation.

The decrease in conjugated diene levels observed in E1 and E2 rats in both basal and oxidative conditions confirmed the protective effect of Se enrichment of the diets, independent from the form of Se. It is plausible that the increase in liver TAA contributed to the protective effect against oxidative stress; in basal condition TAA appeared significantly higher in E1 and E2 rats compared to St ones by Student's $t$ test $(P<0.05$ in both cases), and after ADR administration significant differences were detected among the three groups even by one-way ANOVA.

TAA represents the overall level of defence system against oxidative stress, and both endogenous and exogenous antioxidants contribute to it. In basal condition and after ADR administration $\mathrm{Se}$, both as sodium selenite and lyophilized food, significantly increased GPx activity which, in turn, greatly influenced the entity of global defences against oxidative stress, in agreement with our previous data in Se-supplemented cultured cardiomyocytes $^{28,29}$, and with data obtained in erythrocytes ${ }^{30}$ and liver ${ }^{31}$. A linear correlation was found between GPx activity and TAA in both basal $(r 0.912, P<0.001)$ and oxidative condition $(r 0.964, P<0.001)$.

The increase in GPx activity can explain the reduced ROM and conjugated diene levels observed in E1 and E2 rats, since it is demonstrated that this Se-containing enzyme, which is ubiquitously present but predominantly in liver, functions to detoxify both hydrogen and lipid peroxides ${ }^{32}$. Although both experimental diets increased GPx activity, in an oxidative condition the supplementation with the lyophilized food appeared more efficient than the one with sodium selenite $(P<0 \cdot 05)$.

In St rats GPx activity appeared lower and GSH content higher than in E1 and E2 rats, in agreement with Matsumoto et $a l .{ }^{33}$, who reported that a low-Se diet causes a decrease in GPx activity and an increase in GSH content in the liver. In E1 and E2 rats the decrease in liver GSH concentration paralleled the increase in GPx activity, probably due to an increased GSH utilization as a cofactor by GPx.

Regarding liver total lipid fatty acid composition, it has been suggested that Se could play a role in the desaturation of n-3 and n-6 PUFA ${ }^{7,34}$, and Quilliot et al. ${ }^{35}$ found a negative correlation between Se level and PUFA content in diabetic patients, suggesting that Se could affect desaturase activity. Schafer et al. $^{36}$ reported a decreased desaturase activity in Se-deficient rats fed on a high n-3 PUFA diet, but since it is known that a high-PUFA diet may inhibit desaturation, a direct effect of Se itself on the desaturase enzyme was not surely established. In this work, the lower arachidonic acid relative molar content observed in St rats compared with E1 and E2 ones, together with the higher 18:2/20:4 ratio, allow speculation of a direct effect of Se in linoleic acid conversion. Since St diet was marginally Se deficient, our data suggest the need of adequate Se intake to maintain PUFA metabolism.

In conclusion, our data indicate that an adequate Se dietary intake, in pure chemical form or as a lyophilized, Se-enriched, vegetable food, is able to protect against exogenous pro-oxidants. Our results are in agreement with those obtained by Kocdor $e{ }^{a l} .{ }^{37}$ in rats exposed to 7,12-dimethylbenz[a]anthracene, and confirm that Se plays a major and synergistic role as exogenous antioxidants in the regulation of the endogenous antioxidant defence system ${ }^{38}$.

According to Crosley et $\mathrm{al}^{21}{ }^{21}$, our St diet, containing $50 \mu \mathrm{g}$ $\mathrm{Se} / \mathrm{kg}$, can be considered as marginally deficient, while E1 and E2 diets, containing $100 \mu \mathrm{g} \mathrm{Se} / \mathrm{kg}$, can be considered as adequate. In several EU countries Se intakes are less than half the UK reference nutrient intakes of 60 and $75 \mu \mathrm{g} \mathrm{Se} / \mathrm{d}$ for females and males respectively, and Se intake in the UK has declined from $>60 \mu \mathrm{g} \mathrm{Se} / \mathrm{d}$ in 1974 to $29-39 \mu \mathrm{g} \mathrm{Se} / \mathrm{d}$ (for review, see Rayman ${ }^{39}$ ). Although there is substantial evidence that Se is a potent anti-carcinogen when it is present at levels above those required for the maximal expression of selenoproteins, at present we think that the main nutritional goal is to guarantee adequate Se intake. This result may be reached either using foods or supplements, and it is important to understand if these two strategies give similar functional results.

No dramatic differences due to the different form of Se supplementation were detected, but the increase in GPx activity 
appeared more evident in rats fed on the diet enriched with the lyophilized food, according to our previous data comparing the efficacy of sodium selenite and selenomethionine in cultured cardiomyocytes ${ }^{28,29}$. This could be due to the different chemical forms of Se, the majority of which was allocated to soluble and insoluble protein fractions in the Se-enriched potato used as Se source, or to other components of the food itself. In fact, protection is mediated by the ideal combination of nutrients and phytochemicals in foods and not by a single molecule; some other components of lyophilized potatoes, such as methionine could have also acted as positive modulators of GPx activity ${ }^{40}$.

Although further studies are needed, data herein presented may contribute to the characterization of the effectiveness of Se from different sources, foods or supplements, in the light of dietary advice concerning improvement of Se intake within the population.

\section{Acknowledgements}

This work was partially supported by grants from Italian MIUR 60\% and PRIN 2005, and from 'Consorzio delle Buone Idee' (Bologna, Italy). The authors thanks Dr. Valeria Poggi, Dr. Melissa Mazzoni and Dr. Giorgia Colinucci for their skillful technical assistance.

\section{References}

1. Rakotovao A, Berthonneche C, Guiraud A, de Lorgeril M, Salen P, de Leiris J \& Boucher F (2004) Ethanol, wine, and experimental cardioprotection in ischemia/reperfusion: role of the prooxidant/antioxidant balance. Antioxid Redox Signal 6, 431-438.

2. Scalbert A, Johnson IT \& Saltmarsh M (2005) Polyphenols: antioxidants and beyond. Am J Clin Nutr 81, 215S-217S.

3. Brenneisen P, Steinbrenner H \& Sies H (2005) Selenium, oxidative stress, and health aspects. Mol Aspects Med 26, 256-267.

4. El-Bayoumy K (2001) The protective role of selenium on genetic damage and on cancer. Mutat Res 475, 123-139.

5. Serwatka K, Stachowska E \& Chlubek D (2005) Selenium and the activities of cyclooxygenase and lipoxygenase in cells involved in atherogenesis. Ann Acad Med Stetin 51, 65-68.

6. Ganther HE (1999) Selenium metabolism, selenoproteins and mechanisms of cancer prevention: complexities with thioredoxin reductase. Carcinogenesis 20, 1657-1666.

7. Infante JP (1986) Vitamin E and selenium participation in fatty acid desaturation. A proposal for an enzymatic function of these nutrients. Mol Cell Biochem 69, 93-108.

8. Poggi V, Pifferi PG, Bordoni A \& Biagi PL (1999) Plantderived foods supplied with selenium: the potato [in Italian]. Ind Alim 38, 1107-1113.

9. Navarro-Blasco I \& Alvarez-Galindo JI (2004) Selenium content of Spanish infant formulae and human milk: influence of protein matrix, interactions with other trace elements and estimation of dietary intake by infants. J Trace Elem Med Biol 17, 277-289.

10. Mukherjee S, Banerjee SK, Maulik M, Dinda AK, Talwar KK \& Maulik SK (2003) Protection against acute adriamycin-induced cardiotoxicity by garlic: role of endogenous antioxidants and inhibition of TNF-alpha expression. BMC Pharmacol 3, 16.

11. Erba D, Riso P, Bordoni A, Foti P, Biagi PL \& Testolin G (2005) Effectiveness of moderate green tea consumption on antioxidative status and plasma lipid profile in humans. $J$ Nutr Biochem 16, 144-149.

12. Folch J, Lees M \& Sloane Stanley GH (1957) A simple method for the isolation and purification of total lipides from animal tissues. J Biol Chem 226, 497-509.

13. Re R, Pellegrini N, Proteggente A, Pannala A, Yang M \& RiceEvans C (1999) Antioxidant activity applying an improved ABTS radical cation decolorization assay. Free Radic Biol Med 26, 1231-1237.

14. Flohe L \& Gunzler WA (1984) Assays of glutathione peroxidase. Methods Enzymol 105, 114-121.

15. Akerboom TP \& Sies H (1981) Assay of glutathione, glutathione disulfide, and glutathione mixed disulfides in biological samples. Methods Enzymol 77, 373-382.

16. Burton KP, McCord JM \& Ghai G (1984) Myocardial alterations due to free-radical generation. Am $J$ Physiol 246, H776-H783.

17. Stoffel W, Chu F \& AhrensEH (1959) Analysis of long-chain fatty acids by gas-liquid chromatography. Anal. Chem. 31, 307-308.

18. Bordoni A, Lopez-Jimenez JA, Spano C, Biagi P, Horrobin DF \& Hrelia S (1996) Metabolism of linoleic and alpha-linolenic acids in cultured cardiomyocytes: effect of different N-6 and N-3 fatty acid supplementation. Mol Cell Biochem 157, 217-222.

19. Aboul-Fadl T (2005) Selenium derivatives as cancer preventive agents. Curr Med Chem Anticancer Agents 5, 637-652.

20. de Lorgeril M, Salen P, Accominotti M, Cadau M, Steghens JP, Boucher F \& de Leiris J (2001) Dietary and blood antioxidants in patients with chronic heart failure. Insights into the potential importance of selenium in heart failure. Eur J Heart Fail 3, 661-669.

21. Crosley LK, Meplan C, Nicol F, Rundlof AK, Arner ES, Hesketh JE \& Arthur JR (2007) Differential regulation of expression of cytosolic and mitochondrial thioredoxin reductase in rat liver and kidney. Arch Biochem Biophys 459, 178-188.

22. Beilstein MA \& Whanger PD (1986) Chemical forms of selenium in rat tissues after administration of selenite or selenomethionine. J Nutr 116, 1711-1719.

23. Whanger PD (2002) Selenocompounds in plants and animals and their biological significance. $J$ Am Coll Nutr 21, 223-232.

24. Whanger PD (2004) Selenium and its relationship to cancer: an update dagger. Br J Nutr 91, 11-28.

25. Turakainen M, Hartikainen H, Ekholm P \& Seppanen MM (2006) Distribution of selenium in different biochemical fractions and raw darkening degree of potato (Solanum tuberosum L.) tubers supplemented with selenate. J Agric Food Chem 54, $8617-8622$.

26. Whitin JC, Tham DM, Bhamre S, Ornt DB, Scandling JD, Tune BM, Salvatierra O, Avissar N \& Cohen HJ (1998) Plasma glutathione peroxidase and its relationship to renal proximal tubule function. Mol Genet Metab 65, 238-245.

27. Samouilidou E, Grapsa E, Karpouza A \& Lagouranis A (2007) Reactive oxygen metabolites: a link between oxidative stress and inflammation in patients on hemodialysis. Blood Purif. 25, 175-178

28. Bordoni A, Biagi PL, Angeloni C, Leoncini E, Muccinelli I \& Hrelia S (2003) Selenium supplementation can protect cultured rat cardiomyocytes from hypoxia/reoxygenation damage. J Agric Food Chem 51, 1736-1740.

29. Bordoni A, Biagi PL, Angeloni C, Leoncini E, Danesi F \& Hrelia S (2005) Susceptibility to hypoxia/reoxygenation of aged rat cardiomyocytes and its modulation by selenium supplementation. J Agric Food Chem 53, 490-494.

30. Zawadzka-Bartczak E (2005) Activities of red blood cell antioxidative enzymes (SOD, GPx) and total anti-oxidative capacity of serum (TAS) in men with coronary atherosclerosis and in healthy pilots. Med Sci Monit 11, CR440-CR444. 
31. Vali L, Taba G, Szentmihalyi K, Febel H, Kurucz T, Pallai Z, Kupcsulik P \& Blazovics A (2006) Reduced antioxidant level and increased oxidative damage in intact liver lobes during ischaemia-reperfusion. World J Gastroenterol 12, 1086-1091.

32. Arthur JR (2000) The glutathione peroxidases. Cell Mol Life Sci 57, $1825-1835$

33. Matsumoto K, Suzuki A, Washimi H, Hisamatsu A, Okajo A, Ui I \& Endo K (2006) Electron paramagnetic resonance decay constant and oxidative stresses in liver microsomes of the selenium-deficient rat. J Nutr Biochem 17, 677-681.

34. Celik S, Yilmaz O, Asan T, Naziroglu M, Cay M \& Aksakal M (1999) Influence of dietary selenium and vitamin $E$ on the levels of fatty acids in brain and liver tissues of lambs. Cell Biochem Funct 17, 115-121.

35. Quilliot D, Walters E, Bohme P, Lacroix B, Bonte JP, Fruchart JC, Drouin P, Duriez P \& Ziegler O (2003) Fatty acid abnormalities in chronic pancreatitis: effect of concomitant diabetes mellitus. Eur J Clin Nutr 57, 496-503.
36. Schafer K, Kyriakopoulos A, Gessner H, Grune T \& Behne D (2004) Effects of selenium deficiency on fatty acid metabolism in rats fed fish oil-enriched diets. J Trace Elem Med Biol 18, 89-97.

37. Kocdor H, Cehreli R, Kocdor MA, Sis B, Yilmaz O, Canda T, Demirkan B, Resmi H, Alakavuklar M \& Harmancioglu O (2005) Toxicity induced by the chemical carcinogen 7,12dimethylbenz[a]anthracene and the protective effects of selenium in Wistar rats. J Toxicol Environ Health A 68, 693-701.

38. Goldfarb AH (1999) Nutritional antioxidants as therapeutic and preventive modalities in exercise-induced muscle damage. Can J Appl Physiol 24, 249-266.

39. Rayman MP (2004) The use of high-selenium yeast to raise selenium status: how does it measure up? Br J Nutr 92, $557-573$.

40. Seneviratne CK, Li T, Khaper N \& Singal PK (1999) Effects of methionine on endogenous antioxidants in the heart. Am J Physiol 277, H2124-H2128. 